\title{
De quem é a Riqueza que Está Ali? Discutindo responsabili- dades na Exploração de Minério no Sul Global
}

\section{Whose is that wealth? Discussing responsibilities and mi- ning in the Global South}

\author{
Nicole Spohr \\ Doutorado em administração de empresas na FGV-EAESP. Professora na FGV-EBAPE, nicole.spohr@gmail.com \\ http://lattes.cnpq.br/1372719575277298
}

\section{Amon Barros}

Doutorado em administração pelo CEPEAD-UFMG. Professor assistente - FGV-EAESP, amonbarros@gmail.com

Marcus Vinícius Peinado Gomes

Doutorado em administração pública pela FGV-EAESP. Professor na FGV-EAESP, marcus.gomes@fgv.br http://lattes.cnpq.br/5230203400615261

Resumo: Este caso para ensino descreve uma situação de conflito envolvendo uma mineradora, uma organização da sociedade civil e uma comunidade afetada pelas operações da empresa. Embora o foco esteja no gerente da multinacional brasileira, o caso abre espaço para reflexão sobre a atuação de cada uma das personagens. Tendo como fonte de dados coleta de documentos e entrevistas in loco, o caso é direcionado a estudantes de Administração, Administração Pública e Relações Internacionais, especialmente em relação aos temas de empresas e direitos humanos, responsabilidade social empresarial, cidadania corporativa e negócios internacionais.

Palavras-chave: mineradoras; Relação empresa-comunidade; Governança Global; Multinacionais.

Abstract: This teaching case describes a conflict involving a mining company, a civil society organization and the community affected by the company's operations. Although the focus is on the manager of the Brazilian multinational, the case leaves room for reflection on the performance of any of the characters. The data was collected from documents and on-site interviews, and the case is directed to management students, Public Administration students and International Relations students, especially on the issues of business and human rights, corporate social responsibility, corporate citizenship and international business. Palavras-chave: Mineradoras; Relação Empresa-comunidade; Governança Global; Multinacionais. Key Words: Mining Companies; Business and Society; Global Governance; Multinationals.

\section{Introdução}

Fevereiro de 2013, nove horas da manhã. Paulo, Diretor de Operações da Bandeirante, olha pela janela da sua sala e vê um grande grupo de pessoas aglomeradas em frente aos portões da empresa. Os manifestantes carregam pedaços de pau, cartazes e faixas e parecem enfurecidos. Paulo consegue ler em uma das faixas os dizeres: "Queremos casas dignas e direito de plantar na nossa terra". Como Paulo pode responder aos protestos de modo a assegurar a continuidade das operações da Bandeirante no Nzambi?

\section{A Chegada da Bandeirante ao Nzambi}

Paulo decidiu mudar-se para a África a fim de crescer profissionalmente. Diretor de Operações da multinacional brasileira Bandeirante, ocupa o segundo cargo mais importante da empresa no Nzambi, um país africano no qual foram encontradas jazidas de diversos minerais. Apesar de responder para o vice-presidente da Bandeirante, Paulo tem um relacionamento muito próximo com o presidente mundial da empresa. Foi ele quem o escolheu para gerenciar todas as atividades operacionais da empresa no país. Paulo está no Nzambi desde 2010, ano em que a Bandeirante ganhou o direito de extrair um minério conhecido localmente como "mika".

A ida da Bandeirante para o Nzambi reflete uma tendência de reaproximação das relações entre Brasil e África. Durante seu governo (2003-2010) o ex-presidente Luís Inácio Lula da Solva realizou 34 viagens ao continente africano. Todos os presidentes brasileiros juntos haviam visitado a região 15 vezes (Rossi, 2015). Em uma destas visitas, o presidente declarou: "O Brasil tem um compromisso moral e ético com o continente africano" (Visentini, 2010, tradução nossa). A ajuda brasileira foi justificada pela ideia de reparação histórica por trezentos anos de escravidão. Ou seja, - Brasil retribuiria ajudando a promover o desenvolvimento econômico, saúde, educação e agricultura (Rossi, 2015). Além disso, a África tornou-se o principal destino dos investimentos brasileiros em 2012ii. Entre 2007 e 2012, a atividade brasileira na região cresceu $10,7 \%$ ao ano, tendo dobrado desde o ano 2000 (Alves, 2012). Para alguns, o país está se arriscando a ser taxado de colonialista.iii

Os setores extrativo e de construção civil têm sido o foco dos investimentos das multinacionais brasileiras. A própria decisão da Bandeirante em concorrer a uma licença para extrair mika no Nzambi ocorreu em parte por conta do estreitamento das relações

Correspondência/Correspondence: Nicole Spohr, Escola de Administração de Empresas de São Paulo. Av. Nove de Julho, 2029 - Bela Vista, São Paulo - SP, 01313-902 
entre os governos. Além disso, a ida de uma empresa do porte da Bandeirante para o Nzambi acabou por fomentar as relações diplomáticas, na medida em que atraiu outras empresas internacionais para atuarem na cadeia de suprimentos da Bandeirante.

No ano de 2002 a descoberta de grandes jazidas de mika no Nzambi, minério muito importante para a indústria mundial, ficou conhecida como "boom mineral". A euforia da população local foi grande já que o país esteve sob o domínio colonial europeu até a década de 1960 e conflitos internos afetaram a região nas décadas seguintes. Tantas riquezas naturais pareciam assegurar 0 crescimento econômico e a melhoria das condições de vida da população. O passado marcado por guerras fez com que houvesse um déficit significativo em termos de infraestrutura e logística para a condução de negócios, sendo este um dos desafios que a Bandeirante, disposta a explorar o minério, passou a enfrentar.

Para a mineradora, o projeto era estratégico. Apesar de já estar presente no continente africano há duas décadas em negócios menores e geralmente com parceria de empresas locais, o presidente da multinacional vinha questionando os novos investimentos na região por conta dos custos envolvidos na construção da mina. Amargando prejuízos desde 2010, quando se instalou no Nzambi, a Bandeirante enfrentava dificuldades para escoar a produção para outras partes do mundo, por conta da infraestrutura precária. Entretanto, o potencial da mina era grande, já que aquela era a última jazida de grande porte de mika inexplorada no mundo. Paulo comentou com sua esposa: Se a operação apresentar resultados positivos este ano, creio que terei condições de assumir o lugar do vice-presidente, que está prestes a se aposentar.

\section{Governo e a Sociedade Civil no Nzambi}

O primeiro desafio que Paulo encontrou ao chegar no Nzambi, país africano com cerca de 20 milhões de habitantes, foi o relacionamento com o governo local. Logo na primeira reunião, Paulo se impressionou com a formalidade das tratativas. Além disso, as táticas de negociação, os prazos para fechamento de acordos, assim como a legislação eram distintos quando comparados ao Brasil. Apesar disso, um dos políticos do Nzambi assegurou a Paulo que ele teria carta branca do governo para realizar os investimentos. Foi dito ainda que a Bandeirante poderia sugerir as mudanças necessárias para construir a mina, inclusive legislativas.

O governo não estava acostumado a tratar com multinacionais do porte da Bandeirante. Havia pouco pessoal qualificado nos ministérios para lidar com demandas até então desconhecidas no Nzambi. Técnicos estavam sendo treinados para gerenciar licenças, fiscalizar as fases de exploração, produção, vendas e exportações de minério. Contudo, o treinamento dependia de bolsas de estudos cedidas pelas próprias empresas extrativas, o que poderia comprometer a independência dos trabalhos.

Uma das críticas ao governo por parte da população local era que o contrato firmado entre este e a Bandeirante não era público. Assim, a sociedade não tinha acesso aos termos negociados. Outra crítica da sociedade dizia respeito aos incentivos fiscais que a Bandeirante passou a desfrutar. Exemplo disso é que a multinacional pressionou o governo para aprovar o direito de explorar mika em condições favoráveis à Bandeirante - sendo que, no dia seguinte à aprovação, uma nova legislação entrou em vigor no país restringindo benefícios fiscais para outras empresas mineradoras. O boom mineral também levantou discussões acerca da dependência dos recursos naturais e sobre a forma com que os royalties gerados por sua exploração deveriam ser utilizados na economia nacional.

Em meados de 2011, Malika, uma jovem bióloga nzambicana que tornou-se ativista social e ambiental a partir de vivências em países africanos vizinhos ao Nzambi, reuniu-se com um grupo de ambientalistas locais para conversar: Tive acesso a um documento que diz que $70 \%$ das terras do Nzambi foram destinadas a empresas estrangeiras para explorarem minérios, dá pra acreditar? - teria esbravejado Malika na ocasião.

Indignado com o fato, o grupo decidiu agir. Considerando que no Nzambi os recursos minerais e o subsolo pertencem à União, o país pode consentir ao minerador o direito de aproveitar industrialmente seus minérios caso acredite que será em benefício de toda a população. Cabe mencionar que a democracia no Nzambi ainda está em seus primeiros anos. As instituições existentes são, muitas vezes, carentes de infraestrutura, recursos e pessoal qualificado. As legislações ambiental e trabalhista estão pouco consolidadas e grande parte da população local depende da terra para plantar e sobreviver. Com isso em mente, o grupo decidiu criar a ONG Niara em 2011, após a chegada de grandes mineradoras como a Bandeirante, para proteger o meio ambiente e quem dele depende. Niara significa "a que tem grandes propósitos".

Desde o início de suas atividades, a Niara tem tido a maior parte de seus trabalhos financiados por doações de uma fundaçãoe estadunidense. A fundação tem atuação independente e se sustenta por meio de fundos próprios, mas cultiva laços políticos com o governo daquele país. A Niara trabalha principalmente por meio da publicação de artigos, boletins, envio de cartas e convites ao governo para participar de seminários e workshops sobre os assuntos considerados sensíveis ao país e à população. Quando necessário, a organização recorria ao Ministério do Meio Ambiente, ao Tribunal Administrativo, à Procuradoria da República e aos órgãos competentes. Por conta disso, muitas vezes a ONG foi considerada como "anti-desenvolvimento", em especial por parte do governo e das empresas interessadas em explorar os recursos naturais do país. Apesar disso, Malika continuava firme na realização de seu trabalho à frente da Niara.

\section{Os Impactos da Bandeirante no Nzambi}

A região em que se encontravam as jazidas minerais concedidas à Bandeirante passou por transformações desde a chegada de Paulo em 2010. Diversas famílias residiam e trabalhavam na área que veio a ser parte da concessão. Uma destas famílias era a de Zaki, líder da comunidade em que vivia. Com trinta e dois anos, o agricultor nasceu e cresceu na região assim como seus pais, avós e bisavós. Boa parte dos antepassados 
de Zaki estava enterrada no quintal da casa em que viviam. Este era um costume local e Zaki esperava que seus três filhos - o mais velho com cinco anos, o segundo com três e o caçula, que ainda estava no ventre de sua esposa - continuassem seguindo esta e outras tradições.

A casa em que ele vivia com a família era de pau a pique, estrutura baseada no entrelaçamento de madeiras verticais, cujos vãos eram preenchidos com barro. O principal meio de subsistência de Zaki e da comunidade era o plantio nas hortas, tal qual $65 \%$ da população nzambicana. Entre as principais culturas estavam mandioca, inhame, milho, quiabo e batata doce. Além disso, as famílias viviam de pesca, pequenas trocas, venda do excedente do plantio no mercado central da cidade, criação de gado e coleta de frutas silvestres. Nas adjacências da comunidade passava um grande rio, que servia como fonte de água para consumo, higiene, pesca e transporte.

Para que a Bandeirante pudesse dar início às obras que possibilitariam a extração do minério, seria necessário realocar centenas de famílias como a de Zaki que viviam e trabalhavam na região de concessão. Logo após a chegada da empresa, teve início um processo de cadastramento das famílias. Este trabalho foi realizado por uma empresa terceirizada especializada neste tipo de atividade, chamada Mind. Foi montado um grupo de trabalho entre o governo do Nzambi e a Mind, que se reunia com os líderes das comunidades - Zaki entre eles - para explicar como seria o reassentamento para um novo bairro construído para receber os moradores.

No Nzambi não havia lei específica sobre realocação da população com o objetivo de exploração econômica do solo. Por isso, o governo baseou-se em uma lei que tratava do remanejamento de pessoas em casos de desastres naturais. Foram construídas maquetes para mostrar como seria o novo bairro e a distribuição das casas. O grupo ouvia as dúvidas e sugestões da comunidade e trabalhava em cima delas para melhorar o projeto do reassentamento.

As conversas foram conduzidas em inglês, idioma dos funcionários da Mind. Apesar de esta ser uma das línguas oficiais do país, não era a primeira língua de muitos membros da região. Alguns termos do acordo não ficaram claros para Zaki que não sabia, por exemplo, se valeria à pena plantar as sementes no próximo período de plantio ou se no momento da colheita a comunidade já estaria alocada no novo bairro. Zaki dividiu suas dúvidas com o cunhado: Com tantas incertezas, como vou garantir comida suficiente para toda a família até a mudança para o novo bairro?

Ainda em 2010, teve início a construção da mina e dos prédios em que a companhia faria a gestão da operação. A fase inicial de montagem demandou um grande volume de mão-de-obra. Por conta disso, Paulo solicitou ao pessoal de Recursos Humanos que buscasse na comunidade que viria a ser reassentada funcionários com baixa qualificação técnica para trabalharem na obra. Familiares e conhecidos de Zaki foram contratados como carpinteiros, cozinheiros e eletricistas. A comunidade ficou satisfeita em fazer parte da construção. Emprego para todos, aliás, foi uma das promessas feitas pela Mind à época do cadastramento, assim como casas de alvenaria, escola próxima ao bairro e clínica médica.

\section{O Reassentamento}

Em uma tarde quente de 2011 os 2891 moradores da comunidade de Zaki foram convidados pela Mind a deixarem suas casas com destino ao novo bairro. Muitas pessoas não quiseram sair do local - diziam que não estavam prontas. Algumas fecharam as portas de suas casas aos funcionários, outros simplesmente fugiram. Muitas questões ainda estavam em aberto: onde eles iriam plantar suas hortas? Haveria acesso à água para todos? Os membros de uma mesma família conseguiriam casas próximas umas das outras? Nenhuma destas questões havia sido respondida pelo governo e pela Mind até o dia da mudança. Apesar da resistência, o governo enviou uma força policial ao local e pressionou a população para que a realocação acontecesse na data marcada.

Os atrativos do novo bairro foram a instalação de escolas primária e secundária, posto policial e centro de saúde, que contava com uma ambulância à disposição dos moradores. A esposa de Zaki ficou contente ao ver o centro de saúde tão perto da sua casa: deste modo, ela poderia ficar tranquila já que teria atendimento rápido quando o nascimento de seu terceiro filho se aproximasse. Os filhos de Zaki não precisariam mais caminhar três quilômetros até a escola, já que o novo centro de ensino estava localizado no mesmo bairro em que a família passou a residir.

Dois meses após o reassentamento Paulo afirmou aos jornais locais que estava satisfeito com as novas instalações do bairro: Tenho certeza que boa parte dos moradores do Nzambi jamais imaginaram morar em uma casa como a que construímos para eles. Sem dúvida o novo bairro é um sonho virando realidade para a população. Todos estes investimentos demonstram o comprometimento da Bandeirante com o desenvolvimento do país.

A matéria ainda mostrava fotos das casas de pau a pique ao lado das casas de alvenaria, sugerindo uma melhoria no padrão de vida local. Na mesma época, a construção da mina estava chegando ao fim e a maioria dos trabalhadores com baixa qualificação foi dispensada, incluindo o cunhado de Zaki. Para cada família cadastrada, foi entregue somente metade da terra prometida para moradia e cultivo. Quando questionado, o governo respondeu que não havia mais espaço para a destinação dos outros hectares para cada família, já que boa parte das terras daquela área do país estava concedida a outras empresas.

Menos de um ano após o reassentamento, em 2012, as novas casas começaram a apresentar rachaduras. Os vizinhos de Zaki passaram a reclamar que não se sentiam seguros nas novas moradias. Quando chovia, não era incomum entrar água nas casas. Além disso, foram instaladas torneiras a serem usados por grupos de famílias, do lado de fora das casas. Em muitas ocasiões, a bomba quebrava e dias se passavam sem que houvesse água disponível. Outro problema era que, no novo bairro, a terra era bastante árida e pouco propícia à agricultura. A falta de irrigação adequada dificultava ainda mais o plantio. A avó de Zaki, ao se queixar que passava fome, comentou: Seria melhor se o Nzambi 
não fosse abençoado com tanto mika! Prefiro minha casa de barro a esta aqui, cheia de rachas!

Cestas básicas foram distribuídas para parte da comunidade, mas não havia regularidade nem informação sobre quando e quantas seriam entregues. A renda da comunidade como um todo diminuiu. Além da dificuldade em plantar, o mercado central da cidade agora estava a vários quilômetros de distância do novo bairro o que dificultava os pequenos negócios.

\section{Os Conflitos}

Diante das reclamações, em janeiro de 2013 Zaki decidiu ir até a sede da Bandeirante. Enquanto tentava agendar uma reunião com um funcionário da empresa, conheceu Malika. Não foi necessária nem meia hora de conversa para que ambos percebessem que partilhavam das mesmas preocupações. No dia seguinte, Malika e seus colegas da Niara foram até o novo bairro e se reuniram com os líderes da comunidade. Elaboraram um documento em que listavam suas principais reivindicações - acesso confiável à água, casas seguras, terra fértil para plantar - e o entregaram a um funcionário da Bandeirante. Tentaram novamente agendar um encontro com os responsáveis pelo reassentamento, porém sem sucesso.

Preocupada com a vinda de mais e mais multinacionais para seu país, Malika descobriu em suas pesquisas que a Organização das Nações Unidas (ONU, 2011) havia aprovado um Guia de Princípios sobre Negócios e Direitos Humanos. Os princípios gerais, que estabeleciam um padrão global a respeito dos papéis das empresas e dos governos, incluíam: a) a obrigação do Estado em respeitar, proteger e assegurar os direitos humanos; b) a responsabilidade corporativa de respeitar os direitos humanos, ou seja, atuar com diligência para evitar infringir os direitos dos outros e tratar os impactos adversos com os quais estão envolvidos; e c) a necessidade de maior acesso pelas vítimas a efetiva reparação, tanto judicial quanto não judicial.

Malika se deu conta de que este foi um dos maiores reassentamentos já realizados no Nzambi. Sem uma legislação específica e sem ter acesso ao contrato firmado entre o governo e a Bandeirante, ficava difícil para a Niara cobrar explicações dos responsáveis. Mas Malika tinha certeza de que violações estavam sendo cometidas. Na Declaração Universal de Direitos Humanos exposta no mural da Niara, o artigo XXV dizia: "Todo ser humano tem direito a um padrão de vida capaz de assegurar-lhe, e a sua família, saúde e bem-estar, inclusive alimentação, vestuário, habitação, cuidados médicos e os serviços sociais indispensáveis [... $]^{\text {wiv }}$. Além disso, um caso importante e de repercussão nacional como este poderia chamar a atenção para o trabalho que a Niara vinha realizando e aumentar as doações para que a ONG pudesse ampliar sua atuação.

Além disso, Paulo estava preocupado, pois se alcançasse repercussão suficiente, o caso poderia afetar a capacidade da

\footnotetext{
' Este caso baseia-se em uma história real. Entretanto, para garantir a anonimato dos envolvidos, nomes, datas e fatos foram alterados

ii De acordo com Sheller (2012).

iii Esta visão é discutida por Alencastro (2012) em texto para a Folha de São Paulo.
}

Bandeirante de conseguir financiamento para bancar suas operações, já deficitárias. Um número crescente de gestores de ativos europeus passou a se preocupar com os aspectos éticos dos investimentos, a exemplo do fundo soberano da Noruegav.

$\mathrm{Na}$ semana seguinte, em um comunicado escrito, a Bandeirante respondeu que dependia do governo para alocar a terra restante a cada família reassentada. Afirmou ainda que as instalações hidráulicas haviam sido construídas de acordo com o plano previamente acordado entre as partes. Informou ainda que enviaria um técnico da empresa para vistoriar as casas que apresentavam defeitos. A Niara enviou o mesmo documento para o governo, que respondeu que as demandas da comunidade deveriam ser repassadas à Bandeirante, já que ela era a responsável pelo reassentamento. No mesmo dia, a mais alta autoridade local declarou que as famílias deveriam ter ficado contentes com o que a Bandeirante havia fornecido, já que claramente as casas novas eram superiores às anteriores. Alguns problemas acontecem, mas este é o preço do desenvolvimento minimizou o prefeito.

\section{De Volta ao Escritório}

Enquanto ainda olha pela janela, Paulo ouve o telefone tocar e pensativo observa novamente os manifestantes. Zaki e Malika estão entre o grupo que pressiona o portão de entrada da Bandeirante. Sua secretária informa que há uma jornalista da BBC na linha querendo entrevistá-lo sobre o protesto e Paulo é chamado de volta à realidade. Quais poderiam ser os riscos desta história ser divulgada pela mídia mundial?

Enquanto isso, nos portões da sede da empresa, Zaki está tenso. Ele nunca se envolveu diretamente em manifestações e por gerações sua família viveu quase completamente dentro das fronteiras da comunidade que circundava o rio do qual foi afastado. Contudo, agora estava impedido de viver tanto de sua pesca como de sua terra. O local para onde foi transferido não permitia o plantio sem que fossem utilizados fertilizantes a cada colheita, os quais sua família não tinha condições de pagar. Zaki quer ser ouvido pela empresa e pelo governo, pois acredita que suas demandas são legítimas. Em seu íntimo, nutre o sonho de candidatar-se a prefeito de sua cidade, já que o atual demonstrou que está do lado da Bandeirante.

Malika vê a manifestação como uma grande oportunidade. Utilizando os contatos que conseguiu atuando na Niara, avisou uma jornalista da BBC sobre a data e as razões do protesto. Espera com isso aumentar a pressão sobre o governo e sobre a empresa para forçá-los à mesa de negociação, na esperança de conseguir termos favoráveis tanto aos reassentados, como também para proteger as comunidades das futuras intervenções de multinacionais como a Bandeirante no país.

iv ONU (2015, p. 13).

$\checkmark$ O fundo administra um patrimônio de cerca de um trilhão de dólares e recentemente reviu seus investimentos em empresas de mineração (Reuters, 2014). 